Original Articles

\title{
Nurses' performance on hospital discharge: patients' Point of view*
}

\author{
Atuação do enfermeiro na alta hospitalar: reflexões a partir dos relatos de pacientes \\ La actuación del enfermero en el alta hospitalario: reflexiones a partir de relatos de pacientes

\begin{abstract}
Daniele Alcalá Pompeo', Maria Helena Pinto², Claudia Bernardi Cesarino³, Renilda Rosa Dias Ferreira de Araújo ${ }^{4}$, Nadia Antonia Aparecida Poletti ${ }^{5}$
\end{abstract}

\begin{abstract}
Objective: To know the hospital discharge process in place and the nurses' performance in preparing patients for discharge. Methods: A descriptive study using semi-structured interviews was used to collect data from 43 patients of medical-surgical units of a major teaching hospital in the state of São Paulo, Brazil. Results: The majority of patients (83.72\%) received tailored discharge instructions. However, a great number of patients (72.08\%) reported discharge instructions were not given by nurses. Almost a half of patients (48.84\%) reported that discharge instructions were given by their physicians. Conclusion: The findings of this study provide insights to improve the educational process of new nurses and their preparation to provide effective discharge instructions. There is also a need to design and implement a hospital discharge process that promotes the participation of interdisciplinary health care providers who are involved in patient clinical care. This discharge process might be an effective way to change health care providers' attitude toward discharge instructions.

Keywords: Patient discharge; Nursing care; Nursing; Health need assessment; Patient care planning
\end{abstract}

\section{RESUMO}

Objetivo: O estudo teve como objetivo conhecer o processo de preparo do paciente para a alta hospitalar e a atuação do enfermeiro de um hospital de grande porte do interior do Estado de São Paulo. Métodos: Estudo descritivo, no qual foi realizada uma entrevista semiestruturada com 43 clientes, que se encontravam com alta hospitalar. Resultados: Segundo os relatos dos clientes, 83,72\% receberam orientações para a alta hospitalar, 48,84\% receberam orientações do médico e 72,08\% não relataram a participação do enfermeiro no processo de orientação para a alta. Observou-se que as orientações são realizadas individualmente, segundo a visão de cada profissional. Considerações finais: Os resultados deste estudo levam a uma reflexão sobre o ensino desenvolvido na formação do enfermeiro sobre o preparo do paciente para a alta, e assim, a necessidade de sistematizar este trabalho da equipe de saúde, o que implica em mudanças de atitudes destes profissionais.

Descritores: Alta do paciente; Cuidados de enfermagem; Enfermagem; Determinação de necessidades de cuidados de saúde; Planejamento de assistência ao paciente

\section{RESUMEN}

Objetivo: En este estudio se tuvo como objetivo conocer el proceso de preparación del paciente para el alta hospitalaria y la actuación del enfermero de un hospital de gran porte del interior del Estado de Sao Paulo. Métodos: Estudio descriptivo, en el que se llevó a cabo una entrevista semiestructurada con 43 clientes, que se encontraban de alta hospitalaria. Resultados: Según los relatos de los clientes, el 83,72\% recibieron orientaciones para el alta hospitalaria, el 48,84\% recibieron orientaciones del médico y el 72,08\% no relataron la participación del enfermero en el proceso de orientación para el alta. Se observó que las orientaciones son realizadas, individualmente según la visión de cada profesional. Consideraciones finales: Los resultados de este estudio llevan a reflexionar sobre la enseñanza desarrollada en la formación del enfermero sobre la preparación del paciente para el alta, y así, la necesidad de sistematizar este trabajo del equipo de salud, lo que implica en cambios de actitudes de esos profesionales.

Descriptores: Alta del paciente; Cuidados de enfermería; Enfermería; Determinación de necesidades de cuidados de salud; Planificación de la asistencia al paciente

\footnotetext{
* Study carried out at a Hospital in the Interior of State of São Paulo.

${ }^{1}$ Pos-graduate of the Nursing Graduate Program at the University of Sao Paulo (USP)- Sao Paulo (SP) - Brazil.

${ }^{2}$ DNS, Professor at the Nursing Undergraduate Program at the Sao José do Rio Preto College of Medicine (FAMERP)- Sao Jose do Rio Preto (SP)- Brazil. Full Professor at the Paulista University (UNIP)- Sao Paulo (SP)- Brazil.

${ }^{3}$ DNS, Professor at the Nursing Undergraduate Program at the Sao José do Rio Preto College of Medicine (FAMERP)- Sao Jose do Rio Preto (SP)- Brazil.

${ }^{4}$ DNS, Professor at the Nursing Undergraduate Program at the Sao José do Rio Preto College of Medicine (FAMERP)- Sao Jose do Rio Preto (SP)- Brazil.

${ }^{5}$ DNS, Professor at the Nursing Undergraduate Program at the Sao José do Rio Preto College of Medicine (FAMERP)-Sao Jose do Rio Preto (SP)- Brazil.
} 


\section{INTRODUCTION}

The high cost of hospitalizations, in addition to advancements in technology and medical sciences have abbreviated patient hospitalization periods, thus leading to early discharges. Patient care should continue at the household, which would help to avoid rehospitalizations, which significantly elevate health care expenses. This calls for systemized hospital discharge planning, which would guarantee enhanced explanations for patients or families ${ }^{(1)}$.

In clinical practice, it is observed that hospital discharge instructions are given at the moment patients leave the hospital instead of being developed throughout the hospitalization period. This means that many oral instructions are given at the same time, which makes it difficult for patients to understand and, thus, often lead to errors. Discharge instructions are mostly delivered mechanically and hurriedly, without taking each patient's needs into consideration. This disagrees with the literature on this subject, which recommends hospital discharge planning should start as soon as patients are admitted to the institution, and should be developed throughout the hospitalization period ${ }^{(2)}$.

There are few published studies about hospital discharge from the patients' view. Research mainly focuses on the importance of the nurses' role in helping patients and relatives to adjust to and understand about health care outside the hospital.

Most studies on this subject focus on performing hospital discharge plans especially in treatments that imply changing patients' lifestyles, like: oncological diseases ${ }^{(3)}$, laryngectomy $y^{(4)}$, intestinal ostomy $y^{(5)}$, diabetes mellitus( ${ }^{(0)}$, mastectomy ${ }^{(7)}$, coronary arteriosclerosis ${ }^{(8)}$, and vascular surgeries $^{(9)}$. It is known that systematic patient discharge planning could contribute to several aspects, like: the hospital audit section, the nursing profession, and, especially, patient satisfaction.

Discharge plans require interdisciplinary work. In other words, there should be interaction among the professionals involved in the health-disease process to overcome health care fragmentation, and permit discussions about solving problems with a view to understanding the reality experienced by the patient. From this perspective, interdisciplinarity is marked by the feature of incorporating multiple specialties, instruments, health care methods, and articulating knowledge aimed at meeting the patients' domiciliary health care needs ${ }^{(10)}$. To ensure the hospital discharge plan is effectively implemented, a systemized guide should be used, which consists of educational activities and assessment of patients' comprehension about leading an independent life. Nurses should prepare a discharge outline, consisting of a concise and informational summary about patient conditions, focused on the previous education offered to patients and their families. A copy of this outline should be handed to patients or their caretaker ${ }^{(11)}$ to be used as a guide or reminder of daily health care.

It is believed that discharge plans are a tool to guarantee continuous health care after hospitalization. The teaching involved in discharge planning is part of the educational process, which implies patients and their families are instructed about what they need to know and understand, taking biopsycho-spiritual aspects into consideration. In this view, this issue remains a great challenge for nurses, since it is understood that quality health care should be founded on technicalscientific competencies, without risks to patients, relatives, professionals, and institutions.

Based on these considerations, this study sought to learn about the hospital discharge preparation process at a largescale hospital in the state of Sao Paulo and nurses' performance within this context, based on patient reports. Therefore, the purpose of this study is to contribute to the improvement of hospitalized patient care.

\section{METHODS}

This is a descriptive study, developed in clinical and surgical hospitalization units of a large scale hospital in the state of Sao Paulo. This institution is a reference hospital for 102 neighboring cities; it has approximately 700 beds, of which most are used by the Single Health System (SHS). The hospital is also a field for clinical teaching for technical as well as nursing and medicine undergraduate courses. The surgical and medical clinic has approximately 100 beds each, depending on patient needs. The health staff consists of several professional categories, including 27 nurses: four supervisor nurses, 124 nurse auxiliaries, and five nurse technicians. Besides the medical residents (24 in surgery and 32 in internal medicine), there are 33 interns, 18 psychology interns, and 2 nutritionists who assist the entire hospital when requested. The study comprised a convenience sample consisting of 43 patients who had signed hospital discharge, in the data collection period, in May 2004. The inclusion criteria were: being over 18 years of age, be oriented in time and space, communicate verbally, and be aware of their hospital discharge.

Data collection was carried out Monday through Friday afternoons, by means of recorded semi-structured interviews performed at hospitalization units. The interviews lasted between 20 and 40 minutes, and were guided by the questions: "Did you receive instructions for discharge?"; "By whom?"; "At what moment?"; "How was that done?". This study was previously forwarded and approved by the Institutional Review Board at the Sao Jose do Rio Preto College of Medicine (review number 1867/2004) and participants provided written consent.

The interviews were fully transcribed and the informants' statements were then analyzed according to Bardin's ${ }^{(12)}$ content analysis principles, in the thematic analysis mode. From skimming the statements, the data was coded and 
categorized, and thus it was possible to identify the themes that permitted to understand the preparation process that patients received for hospital discharge.

\section{RESULTS}

Before the presentation of the results regarding the preparation process for hospital discharge and the nurses' performance in this context, it is worth describing the main characteristics of the study participants to better understand the data. The latter, along with the subjects' experiences, are considered the factors that most affect the learning needs, which nurses should identify. It is the duty of nurses and all professionals involved in patient treatment to take measures with the aim of meeting those needs.

\section{Informants' characteristics}

Of the 43 participants, $65.12 \%$ were women, and $34.88 \%$ were men. The average age was 48 years, with a standard deviation of 17.5 years. The lowest age was 18 and the highest 78. Education levels ranged from illiterate $(23.25 \%)$ to incomplete superior education (4.65\%). Occupations varied: $44.20 \%$ of the participants were professionally active and remunerated, $37.20 \%$ were retired, and $18.60 \%$ were housewives. The hospitalization period was considered as the day of admission to the day of discharge. The minimum hospitalization period identified was two days, and the maximum was 20 days, with an average of eleven days and standard deviation of 4.23 days.

According to patient records, $46.51 \%$ of the participants were hospitalized for surgical treatment, of which discharge instructions were based on care regarding medications, dressings, and preventing infections.

From the participants' statements, according to the adopted analysis model, three categories emerged, which identify the patient discharge preparation process: the professionals who gave discharge instructions, the received discharge instructions, and the clients' comprehension about the discharge instructions.

The professionals who gave discharge instructions Of the informants, $83.72 \%$ reported having received hospital discharge instructions. Figure 1, below, illustrates that most participants $(48.84 \%)$ reported receiving instructions exclusively from physicians, and $16.28 \%$ reported they did not receive any discharge instructions.

The majority of the informants $(81.40 \%)$ reported receiving instructions from physicians, either with or without other professionals. Patients with specific needs received instructions form other professionals besides the physician, according to the institution's routine; for instance: patients who were discharged with nasogastric feeding-tubes also receive instructions from the nutritionist. This is observed in the statement below:

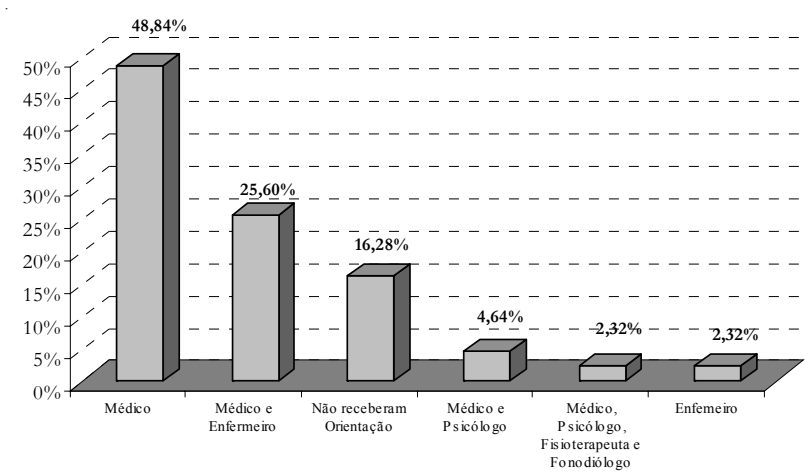

Figure 1 - The professionals who gave hospital discharge instructions, according to patient statements - May/2004.

"The doctor came and handed me the prescription, and then the lady came and explained how to prepare the tube-feeding diet" (S6)

According to the participants' speeches, there was no participation of nurses in $72.08 \%$ of the discharge preparation cases. Although $25.06 \%$ of the subjects reported having received instructions from nurses along with physicians, it should be stressed that during the interview, when subjects were asked if the knew the unit's nurse, they referred to the nurse auxiliary responsible for their care. The clients showed they knew the nurse when they were reminded that she usually wears a "different coat", as in the following statements: "Oh! The one with a coat! Since I came in, she hasn't been in my room" (S24); "Ob! She came here, but I didn't know if she was a nurse or a doctor" (S27).

These statements show that the nurse is not involved with systematic patient discharge planning, and is often confused with other nursing professionals.

\section{The received discharge instructions}

The statements show that preparation for discharge takes place at the moment that the physician tells the client about it, and is limited to simply providing instructions about the medical prescription and follow up visits: "The doctor gave me the prescription and didn't say anything, he told me to go to the health center to change dressings and come back to the outpatient clinic in two weeks" (S10).

It is observed that information is given separately by the professionals: "The doctor stopped by, left the prescription and told me to buy the medication and said that later the lady would come over to explain how to prepare the diet" (S14).

Physicians also provide information about self-care to be carried out after discharge: "The doctor told me that I have to remove the tube every day to wash it, just like he did this morning" (S14).

When psychologists follow the patient, they provide information about the outpatient follow up and instructions to the family: "The psychologist came here, talked a little with my sister and told me that I have to schedule a follow up appointment with her, at the outpatient clinic" (S38). 
Nutritionists are responsible for instructions about how to prepare the diet that the patient will follow after discharge: "The lady (nutritionist) came and just gave me a prescription of what I have to buy to prepare the tube-feeding diet" (S30).

Nurses give discharge instructions regarding the health care they consider complex and need patient adjustment, like ostomies and tubes, as seen in the following statement: "The nurse (stomatherapy specialist) came to explain to me how to change the bag" (S19); "The nurse came tell me that I have to insert the tube and remove the urine every 4 hours [...], but I'm scared, I'll see if I get a nurse to do that at home" (S32).

Based on these statements, it is considered that instructions are provided by the professionals individually and that no instructions are given as a team. It appears each professional explains what is important from their perspective, disregarding the clients' needs. Thus, the statements reveal that nurses give instructions about the complex care involving individual readjustments.

\section{The clients' comprehension about the discharge instructions}

The informants stated that the interview was an opportunity to report doubts, like the following: "I wanted to know about the prescription, the medications, do I leave with them or do I have to buy what's here on the prescription?" (S29).

One client who was only waiting for his wife to leave his room, reported: 'T'd like to know if I can use the crutches without forcing my leg, so I don't step on the floor or bend my leg too much, because the crutches are here, you know?" (S41).

Sometimes the instructions are not understood at the moment they are given, as showed in the following statement: "Oh, a couple of doctors came over and, they spoke, but I didn't understand" (S6).

Discharge instructions are limited to the environment in which hospitalization occurred and there is no way of quickly making contact again with the health team in the case doubts occur at home. One patient statement presented this issue: "At that moment, you don't remember what you need to ask, then you come home and remember the things you forgot to ask about" (S17). "The nurse came here and explained how I should put the bag on, that is something I can do" (S19); "We don't understand it very well, but the pharmacist will explain it to me when I go there to buy the medication". (S35)

The statements show that patients have been leaving the hospital with doubts, especially concerning the instructions about the medical prescription and care for rehabilitation and independence at home.

\section{DISCUSSION}

This study reveals facets of a reality that could result from the lack of significant nurse-patient interactions, in which the interlocutors mutually recognize themselves from the moment of admission. These encounters could be a privileged space to investigate the needs and encourage the expression of patient feelings with a view to their participation in their health care plan, respecting and promoting their autonomy.

According to the patients' statements, professionals have different degrees of participation in discharge preparation, and physicians are those most remembered. Nurses appear to be mostly absent to the process, since they are often confused with nursing auxiliaries and technicians, even with doctors. Perhaps a permanent education program is missing, which could focus on nurse designations regarding patient discharge, since in the studied context there is a ratio of seven to eight patients per nurse.

A study performed with a group of mastectomized women $^{(7)}$ found that physicians were the most active professionals in hospital discharge preparation, who often develop a extremely limited approach. Another study reported that nurses have dedicated more time to bureaucratic administrative activities, like organizing and filling documents, than to those related to patient care and education ${ }^{(13)}$.

Some authors emphasize that nurses have an essential role in the discharge process, sine they are considered the professionals who become closest to patients and the bonding link between the other multiprofessional team members ${ }^{(7)}$. However, this activity was not observed in the present study. This reflects the vicious cycle of the nursing problem, mainly concerning deficiencies in professional formation, which do not permit to apply theory to practice. The impaired communication between health care professionals and the lack of planning were also stated as factors that contribute to the gaps in implementing the discharge $\operatorname{plan}^{(14)}$.

On the other hand, the studied institution is used as a clinical teaching field, but does not follow the philosophy of a teaching hospital, where the activities should be a model for the apprentices. The physician hegemony over decisions still prevails, which health team members follow, indisputably, all medical orders and prescriptions as well as the institution's interests

The lack of a significant interaction between patients and professionals, including nurses, could lead to insecurity at admission and a lack of confidence in the treatment. This encounter with the professional is the space for exploring doubts and uncertainties. However, the patient statements showed they have certain knowledge deficiencies in the moment of hospital-home transition ${ }^{(15)}$.

The evaluation of patient and family needs should not be simplistic, directed exclusively to their physical necessities; rather, it should consider emotional and financial aspects, as well as the family environment ${ }^{(2)}$. Nurses are responsible for evaluating the patients' or caregivers' understanding about self care, the treatment and their importance to guarantee rehabilitation ${ }^{(16)}$.

Each case should be individually analyzed; that is, while planning health care, nurses should evaluate the clients' capacity, 
readiness, and motivation to learn and, above all, determine which teaching-learning approach will be used ${ }^{(17)}$.

This study results are in agreement with those of a study ${ }^{(18)}$ that investigated the discharge preparation of patients subjected to total hip replacement surgery. Both studies demonstrated that nursing care does not comprise systematically teaching treatment continuity to these patients. Moreover, the authors suggested that one nurse should be trained to prepare total hip replacement surgery patients for discharge. This preparation should take place during hospitalization, and aim to meet the patients' educational needs, with a view to guarantee self-care after hospital discharge $\mathrm{e}^{(18)}$.

The discharge plan is a way for the nursing staff to express their care toward patients. It should be developed with basis on patient's as well as families' necessities and preferences, from a prognosis, treatment, and an estimated discharge date determined by the physician ${ }^{(2)}$.

The statements about instruction comprehension show that part of the patients did not understand the instructions they received; they report doubts that will likely appear and many are afraid of saying they did not understand the instructions.

Nurses have are ethically responsible for the patient education process and should carefully determine what they need to know. In addition, nurses should recognize the best moment for patients to learn ${ }^{(19)}$, and use interventions that would guarantee self-care continuity.

These results agree with those of a previous study ${ }^{(16)}$ that analyzed the final nursing instructions for hospital discharge, and the clients' knowledge degree regarding the medications. It concluded that prescription instructions were inadequate and contributed to the lack of patient compliance with the drug therapy at home.

Hence, it is mandatory that instructions be given also to relatives and caregivers present at the moment, so they participate of the patient's recovery process. Hospital discharge brings an ambiguous feeling upon the family. While relatives feel happy and relieved that their loved one is coming home, they also feel afraid and insecure about providing patient care. This ambiguity is often caused by the changes that the disease imposes on family. Knowing how the patient and family perceive hospital discharge provides nurses with the basic information to offer these patients appropriate preparation $^{(8)}$.

Patients reported that the nurses' health care management was deficient. This is in agreement with the data from a previous study ${ }^{(13)}$, which found that most nurse activities are administrative, and that only $1 \%$ participates in medical visits. This could explain their tendency to not perform patient discharge planning.

Discharge planning is acknowledged as an important aspect of nursing care. Nevertheless, it remains a problem, especially in terms of establishing effective nurse-nurse and nurse-patients/caregivers communication ${ }^{(11)}$.

Education is a factor that contributes to patient's noncompliance with treatment, as well as to the low levels of comprehension regarding the disease and health care continuity ${ }^{(19)}$. This issue was not observed in this study; education levels did not affect comprehension, which suggests that the issue under discussion is the lack of information, and the way and moment in which it is given. Anxiety and the wish to go home lead to a lack of concentration by patients and caregivers, as well as the ineffectiveness of discharge instructions. Thus, it is justified that instructions be given progressively, and not only on the day of discharge ${ }^{(19)}$.

In this study, it was observed that discharge instructions were not given as a team, and professionals do not take the client's individual needs into consideration. This supports statements that emphasize that hospital discharge is often seen as a standardized practice. The disadvantage of this instructional practice is to deny that patients are active agents in the process, due to their singularities and specific learning needs, thus they tend to be excluded from the process, or are disregarded ${ }^{(2,8)}$.

\section{FINAL CONSIDERATIONS}

This study showed that patients have been leaving the hospital insecure about continuing their treatment. The statements show that hospital discharge preparation consists of simply handing the patient the medical prescription, the doctor giving verbal information about medication, forwarding patients to specific care, and, finally, performing outpatient clinic follow ups.

According to the majority of the informants, hospital discharge preparation has been offered mostly by physicians, and without enough time to consider each patient's particularities, their comprehension difficulties, their lifestyles, experiences, beliefs, myths, anxiety, and fear.

It is believed that the implementation of the nursing process could improve health care and guarantee a more active and humanized approach. Incorporating the hospital discharge plan in health care planning is essential for effective nursing care, as well as the nurses' commitment to this activity.

As long as there is a lack of nursing professionals to permit systemized health care, and administrators who continue to disregard the need for an adequate staff size for quality health care, patients will continue without access to an important support for their hospital discharge. In addition, this will probably lead to additional costs because of to the number of rehospitalizations due to non-compliance with treatment. This fact leads to a reflection on nursing education regarding preparing patients for domiciliary rehabilitation and, above all, the need to systemize the health team's work, which implies on changing the professionals' behaviors.

This study was no more than a starting point to review nurses' performance in the studied context, the institution's 
philosophy, health care services, the institution administrator's perspectives, as well as professional and client satisfaction, so as to improve patient discharge and perform further studies.

\section{REFERENCES}

1. Chuang KY, Wu SC, Ma AH, Chen YH, Wu CL. Identifying factors associated with hospital readmissions among stroke patients in Taipei. J Nurs Res. 2005;13(2):117-28.

2. Huber DL, McClelland E. Patient preferences and discharge planning transitions. J Prof Nurs. 2003;19(4):204-10.

3. Wilson K, Pateman B, Beaver K, Luker KA. Patient and carer needs following a cancer-related hospital admission: the importance of referral to the district nursing service. J Adv Nurs. 2002;38(3):245-53.

4. Zago MMF. Considerações sobre o ensino do paciente cirúrgico. Rev Esc Enfermagem USP. 1993;27(1):67-71.

5. Cronin E. Best practice in discharging patients with a stoma. Nurs Times. 2005;101(47): 67-8.

6. Silva MO, Dias ZP, Almeida AL, Filgueiras ML. Participação do enfermeiro na equipe multiprofissional do plano de educação, controle e prevenção do diabetes mellitus no HUCFF-RJ. Rev Bras Enfermagem. 1992;45(2/3):133-44.

7. Mamede MV, Clapis MJ, Panobianco MS, Biffi RG, Bueno LV. Orientações pós mastectomia: o papel da enfermagem. Rev Bras Cancerol. 2000;46(1):57-62.

8. Dantas RAS, Stuchi RAG, Rossi LA. A alta hospitalar para familiares de pacientes com doença arterial coronariana. Rev Esc Enfermagem USP. 2002;36(4):345-50.

9. Lee TL, Bokovoy J. Understanding discharge instructions after vascular surgery: an observational study. J Vasc Nurs. 2005;23(1):25-9.

10. Meirelles BHS, Erdmann AL. A questão das disciplinas e da interdisciplinaridade como processo educativo na área da saúde. Texto \& Contexto Enfermagem. 1999; 8(1):14965.

11. Pateman B, Wilson K, McHugh G, Luker KA. Continuing care after cancer treatment. J Adv Nurs. 2003;44(2):192-9.

12. Bardin L. Análise de conteúdo. Lisboa: Edições 70; 1995.

13. Costa RA, Shimizu HE. Atividades desenvolvidas pelos enfermeiros nas unidades de internação de um hospitalescola. Rev Latinoam Enfermagem. 2005; 13(5): 654-62.

14. Watts R, Pierson J, Gardner H. Critical care nurses' beliefs about the discharge planning process: a questionnaire survey. Int J Nurs Stud. 2006; 43(3):269-79.

15. Lyra Júnior DP, Amaral RT, Veiga EV, Cárnio EC, Nogueira MS, Pelá IR. A farmacoterapia no idoso: revisão sobre a abordagem multiprofissional no controle da hipertensão arterial sistêmica. Rev Latinoam Enfermagem. 2006;14(3):435-41.

16. Driscoll A. Managing post-discharge care at home: an analysis of patients' and their carers' perceptions of information received during their stay in hospital. J Adv Nurs. 2000;31(5):1165-73.

17. Silva LMG. Breve Reflexão sobre autocuidado no planejamento de alta hospitalar pós-transplante de medula óssea (TMO): relato de caso. Rev Latinoam Enfermagem. 2001;9(4):75-82.

18. Fielden JM, Scott S, Horne JG. An investigation of patient satisfaction following discharge after total hip replacement surgery. Orthop Nurs. 2003;22(6):429-36.

19. Potter PA, Perry AG. Fundamentos de enfermagem. $5 \mathrm{a}$ ed. Rio de Janeiro: Guanabara Koogan; 2004. p. 394-421. 